\title{
ENVIRONMENTAL FACTORS PREDICTING UNINTENDED PREGNANCIES AMONG IN-SCHOOL FEMALE ADOLESCENTS IN RURAL COMMUNITIES IN SOUTH-SOUTH NIGERIA
}

\section{Patience Uhunoma Oghagbon $^{1 *}$ and Catharine Olukemi Agbede ${ }^{2}$}

\author{
Department of Public Health, School of Public \& Allied Health, Babcock University, Ilisan- \\ Remo, Ogun State, Nigeria
}

*Correspondence Email: oghagbonpat2014@gmail.com; Tel no: +2347032367596

2Email Addresses: agbedec@babcock.edu.ng; Tel no: +2348037136618

Cite this article:

P.U. Oghagbon, C.O. Agbede (2021), Environmental

Factors Predicting

Unintended Pregnancies

Among In-School Female

Adolescents in Rural

Communities in South-South

Nigeria. African Journal of

Health, Nursing and

Midwifery 4(3), 45-53. DOI:

10.52589/AJHNM-

WS9OS4XO.

\section{Manuscript History}

Received: 10 May 2021

Accepted: 28 May 2021

Published: 7 June 2021

Copyright $\odot 2020$ The Author(s). This is an Open Access article distributed under the terms of Creative Commons Attribution-NonCommercialNoDerivatives 4.0 International (CC BY-NC-ND 4.0), which permits anyone to share, use, reproduce and redistribute in any medium, provided the original author and source are credited.
ABSTRACT: Unintended Pregnancy is generally considered to be a high-risk event amongst adolescents due to various factors. Understanding factors predicting unintended pregnancies among inschool female adolescents can provide mechanisms for preventing unintended pregnancies and also providing youth friendly centers. In Nigeria, as a whole, unintended pregnancy among adolescents is a daunting problem. Studies have shown the prevalence of unintended pregnancy among adolescents to be $23 \%$ in the west, $36 \%$ in the southwest and $26 \%$ in the North central part of the country. It also ranges from $17 \%$ in Edo state and $6.2 \%$ in the other Niger Delta states to $49 \%$ in Abia State. The main Objective of this study is to investigate the Environmental factors predicting unintended pregnancies among inschool female adolescents in South-South Nigeria. A cross-sectional study which employed the use of quantitative methods of data collection was conducted among 239 in-school female adolescents who were selected through simple random sampling. Data was collected using a semi-structured validated questionnaire with Cronbach's Alpha that ranged from 0.705 to 0.811 . Data were analysed using descriptive and inferential statistics (logistic regression, correlation and chi-square). The result showed that those with low peer influence as compared with high peer influence were 0.92 times less likely to have unintended pregnancy (Odds ratio; 0.92; CI: 0.78-1.08; p=0.27). Low media influence as compared with those with high media influence had an odds of 1.01 likelihood of unintended pregnancy (Odds ratio=1.01; CI: 0.87$1.17 ; p=0.007$ ), those with low parent support as compared with those with high parent support were 0.96 times less likely to have unintended pregnancy (Odds ratio=0.96; CI: 0.81-1.14, p=0.66). The environmental factor predictor was media influence while peer influence and parents' support were not good environmental predictors of unintended pregnancy. Re-engineering media sources are needed to produce more positive and protective behaviours towards adolescent sexuality.

KEYWORD: Adolescent, Environmental Factors, In-School Female, Predictors, Unintended Pregnancies 


\section{INTRODUCTION}

Adolescence, is the transitional phase of growth and development between childhood and adulthood. The World Health Organization (WHO) defines an adolescent as 'any person between ages 10 and 19 (WHO 2018). Puberty begins at the beginning of adolescence, which now occurs earlier than before.

Globally, 33.9\% of adolescents have reported to have experienced unintended pregnancy (Bearak, et al. 2018) and it is estimated that about 16 million girls 15-19 years old give birth each year, which contributes nearly $11 \%$ of all births worldwide (WHO 2014). Unintended Pregnancy in adolescents, is generally considered to be a high-risk event because of the additional burden imposed by reproduction on a developing body. Adolescents are neither children nor adults, but are in transition to adulthood and they constitute a high-risk group often highlighted in public debates (Ajala 2016).

According to Darroch, et al, (2016), there were 21 million pregnancies among adolescent girls aged 15-19 years in developing countries in 2016; nearly half (49\%) were unintended (43\% in Asia, 45\% in Africa, and 74\% in Latin America and the Caribbean) (Darroch, et al 2016). According to the Ethiopia Demographic Health Survey 2016 finding, the prevalence of adolescents' unintended pregnancy is 13\% (EDHS 2016) and it varies depending on residence, urban 5\%, and rural 15\% (EDHS 2016). Moreover, disparities are seen across regions, with the highest 23\% in Afar, 8\% in Amhara, and the lowest 3\% in Addis Ababa (EDHS 2016). In Ghana, adolescents aged 10 to 19 years constitute $23 \%$ of the total population and the incidence of adolescent unintended pregnancy for those aged 12-19 years is 6.6 percent of all pregnancies in Ghana (Ghana statistical service 2015).

In Nigeria, Adolescent unintended pregnancy is a daunting problem. Studies have shown the prevalence of unintended pregnancy among adolescents to be $23 \%$ in the west, $36 \%$ in the southwest and 26\% in the North central part of the country (Envuladu, et al. 2014). It also ranges from 6.2\% in Niger Delta state to $49 \%$ in Abia State (Nwosu 2017).

In south western Nigeria, $27.4 \%$ unintended pregnancy among adolescents in a secondary school all ended in abortion (Sule, et al 2015), also, in the southern part of Nigeria, about $32 \%$ of the cases of unsafe abortion was among adolescents who had unintended pregnancies.

In Benin City, Edo state, the rate of unintended pregnancy and STI among adolescents is increasingly becoming a major problem. However, the sexual and reproductive health challenges of adolescents have been greatly neglected in Nigeria and not very well understood despite the magnitude (Nwabueze, et.al 2014; Folayan, et.al. 2015).

Adolescent pregnancies are a global problem occurring in high-, middle-, and low-income countries. Around the world, however, adolescent pregnancies are more likely to occur in marginalized communities, commonly driven by poverty and lack of education and employment opportunities. Recent reports (NPC \& ICP, 2018), show that adolescents in rural areas are three times as likely to have begun childbearing than their urban peers; $27 \%$ of rural adolescents have had a live birth or are pregnant, as compared with $8 \%$ of urban adolescents.

Furthermore, it was reported by Darroch, et al. (Darroch, et al 2016). In their study, adolescents who may want to avoid unintended pregnancies may not be able to do so due to knowledge gaps and misconceptions on where to obtain contraceptive methods and how to use them. 
Healthcare providers may also be prohibited from delivering contraceptive services to unmarried adolescents' (Godwin, Szabo et al 2014). The age that an adolescent is allowed to consent for sex often conflicts with the age that the adolescent is allowed to consent for medical interventions (WHO 2015).

Evidences from studies have shown that those who are pregnant as students either dropout of school or are dismissed from school, majority of whom may never get back to school again while others are forced by their parents into child marriage as a result of the pregnancy (Onyeka, Miettola et al 2011).

Peers are usually surrounded by people of the same age especially in school, and social class. They spend most of their time with friends and peers in school and other social gatherings and activities. Adolescents tend to engage in sexual behaviour especially when their close friends are sexually active thus influenced as these ones view sex as normal and exciting. Ahinkorah et al (2019) in their study showed that peer group pressure to have sex had the highest rate of $71 ., 8 \%$ ignorance on uptake of contraceptive by adolescence was $69.3 \%$ on the causes of adolescence unintended pregnancies in Nigeria.

In a research by Blerta P. (2017) it was gathered that peer pressure in school was very common especially in schools that were of different social groups where popular students were known to be the high class and other groups in the lower class. However, adolescents were likely to engage in sexual intercourse when they have the high class as friends that were sexually active. Pressure to engage in this affected both male and female adolescents. In addition, fear of being dropped from the high-class group made them yield to sexual pressure which led to viewing sex as harmless, safe and exciting and this increased their desire to continue with sexual behaviour, thus placing more importance on how to be among the popular peer which can lead to the voluntary acceptance of sexual intercourse among male and females (Blerta P. (2017). Furthermore, a study in the local setting by Alex - Hart, et al, conducted among in-school adolescents in port Harcourt Rivers State, Nigeria found that the commonest reason for having sex was because their friends had also had sex and they want to belong to the class of students (Alex-Hart 2015).

Therefore, this study aimed to investigate the environmental factors predicting unintended pregnancies among in-school female adolescents in rural communities in south-south Nigeria.

The findings of this study, may assist governmental and non-governmental organizations and stakeholders dealing with in-school adolescents' sexual issues to understand ways of carrying out intervention programs that could prevent unintended pregnancies. The study also hypothesized that environmental factors (Media, peers, parents and socio-economic status) would predict unintended pregnancy among in-school female adolescents in rural communities in South-South Nigeria. 


\section{MATERIALS AND METHOD}

\section{Study Design and population}

This study employed a quantitative design to understand the environmental factors predicting unintended pregnancies among in-school female adolescents in rural communities in SouthSouth Nigeria from January 2021 to April 2021.

\section{Study Sample and Technique}

The study participants were in-school female adolescents in both public and private secondary schools in selected rural communities in South-South Nigeria. The sampling technique that was adopted for this study was a multi-stage sampling technique.

Proportionate stratified sampling was used to select the number of students in each school to participate in the study. The proportion for selection was calculated using the number of female students in the schools (SS1-SS3) divided by the total population of female students multiplied by the estimated sample size. A random sampling technique (balloting) was used to select participants from each class. The normal distribution sample size determination method was used so as to avoid type 1 and type 11 error at $95 \%$ level of significance and $80 \%$ power. The sample size for this study was 239. The study was approved by the Health Research Ethics Committee of the authors' institution.

\section{Data collection method}

A semi-structured questionnaire was used to obtain information concerning the environmental factors predicting unintended pregnancies among in-school female adolescents. Each student voluntarily participated in the study following a full description of the study and the consent to continue with the study from the participants was obtained. Each selected student participated in the study for an average of 25 minutes.

\section{Ethical Consideration}

The study was approved by the Health Research Ethics Committee of the authors' institution.

\section{Data analysis}

The data obtained from the respondents were coded and analyzed using statistical package for social science (SPSS) version 23.0 and were also summarized. 


\section{RESULT}

\section{Socio-Demographics of Respondents}

The mean age of respondents was $15.8 \pm 1$.1 years with ages ranging from 13 to 19 years. All $239(100 \%)$ of the respondents were female. Less than half $65(35.1 \%)$ of the respondents are in senior secondary one (SS1), while $37.1 \%$ were in senior secondary three (SS3). The predominant ethnic group among the respondents were Benin 76(31.8). Less than half $105(43.9 \%)$ of the respondents were Christian. Less than half $102(42.7 \%)$ of the respondents lived with both parents (See, Table 1).

\section{Table 1: Demographic Characteristics of Respondents}

\begin{tabular}{lcc}
\hline Demographic Variables for Consideration & Frequency $(\mathrm{n}=239)$ & Percentage $(\%)$ \\
Age (in years) $\mathbf{x}(\mathrm{SD}) \mathbf{1 5 . 8} \pm \mathbf{1 . 1}$ years & 19 & 7.9 \\
$13-14$ & 220 & 92.1 \\
$15-19$ &
\end{tabular}

Sex

Female

\section{Class}

SS2

\section{Ethnicity}

Benin

Esan

Yoruba

Urhobo

Others

\section{Religion}

Christianity 105

Islam

\section{I live with}

Father only 


\section{Environmental factors of Respondents}

The result of the binary logistic regression showed that those with low peer influence as compared with high peer influence had an odds of 0.92 times less likely to have unintended pregnancy (Odds ratio; 0.92; CI: 0.78-1.08; $p=0.27$ ). There was a statistical significant association between peer influence and having unintended pregnancy.

In-school, adolescents with low media influence as compared with those with high media influence had an odds of 1.01 times more likely to have unintended pregnancy (Odds ratio $=1.01$; CI: $0.87-1.17 ; p=0.007)$. However, there was no statistical significant association between media influence and having unintended pregnancy.

In-school, adolescents who had low parent support as compared with those who had high parent support had an odds of 0.96 times less likely to have unintended pregnancy (Odds ratio=0.96; CI: $0.81-1.14, p=0.66$ ). (See table 2). However, there is no statistical significant association between parent support and having unintended pregnancy. Therefore, based on these values, unintended pregnancy is not dependent on the peer and parent support but is dependent on media influence (See table 2).

Table 2: Logistic Regression showing Environmental Predictor of Unintended Pregnancy

\begin{tabular}{lllll}
\hline Variable & \multicolumn{2}{c}{ Unintended Pregnancy } \\
& Odd ratio & p-value & Confidence interval \\
Peer influence & 0.92 & 0.27 & 0.78 & 1.08 \\
Media influence & 1.01 & 0.007 & 0.87 & 1.17 \\
Parent support & 0.96 & 0.66 & 0.81 & 1.14 \\
\hline
\end{tabular}

\section{DISCUSSION}

This study revealed that the majority of the respondents had moderate media influence. There was an association between media and unintended pregnancy. Exposure to indecent and sexbased messages in the media was cited as a predictor in studies conducted by Adongo, (2018) and Mothiba (2012). Both male and female teenagers in rural Ghana expressed a craving to try sexual activities exhibited in scenes from movies or television. (Adongo, 2018). Also, Carroll \& Kirkpatrick (2011) reported that teens that were exposed to a high level of television sexual content were twice likely to experience an unintended pregnancy compared with those with lower levels of exposure.

Peer influence was found not to predict unintended pregnancy in this study. This finding is at variance with the results of Adongo, (20), Mothiba \& Maputle, (21); Kuyinu et al, (22); Ochiogu (23) that peer influence is a predictor to unintended pregnancies among adolescents. The differences in results may be because the adolescents' knowledge of the consequence of unintended pregnancy influences them more than their peers.

Parent support was found not to predict unintended pregnancy. This finding does not corroborate the result of Adongo, (20); Ayele et al., (24) that lack of parental communication 
and support, or poor as predictor of unintended pregnancy. This difference in finding may be because of the difference in study location.

\section{Strength and Limitation}

Strengths of this study include administering a validated questionnaire to participants as guided by standards of quantitative research to gather rich data saturation. On the other hand, the design of the study limits the generalizability of the study to other areas. Some of the adolescents who were sexually active were persuaded through incentives.

\section{CONCLUSION}

Media factors predicted unintended pregnancy most among in-school female adolescents as identified in this study. Incorporating protective sexual health media information into educational interventions can most likely aid in promoting more protective behaviours against unintended pregnancy especially in rural areas.

\section{RECOMMENDATION}

Based on the findings of this study the following are therefore recommended;

1. Educational materials about the negative effects of unintended pregnancy should be included in the curriculum of secondary schools to improve students' knowledge, attitudes and perceptions on unintended pregnancy and to promote abstinence.

2. Parents should create more time to discuss sexual matters with adolescents as well as monitor what they watch or read from time to time. Also parents should serve as good role models.

3. There should be youth friendly clinics established in different communities or Local Government head quarters to promote easy access to contraceptives.

\section{REFERENCES}

Adongo B.W.(2018). Assessing factors influencing early sexual initiation among adolescents (13 to 19 years) in Ghana: a qualitative study. International Journal of Caring Sciences, $2018 ; 11$.

Ahinkorah, B.O., Seidu A. A., Appiah F., Baatiema L., Sambah F., \& Budu E., (2019). What has reproductive health decision-making capacity got to do with unintended pregnancy? Evidence from the 2014 Ghana Demographic and Health Survey.2019; (10)14

Ajala A. O. (2015). Factors associated with teenage pregnancy and fertility in Nigeria. Journal of Economics and Sustainable Development, 2015; 5(2), 22-29.

Alex-Hart, B, A., Okagua, J., \& Opara, P.I.. (2015). Sexual behaviour of secondary school students in Port-Harcourt. British Journal of Medicine and Medical Research, 2015; 6(3),325-334. 
Ayele BG, Gebregzabher TG, Hailu TT, (2018). Determinants of teenage pregnancy in Degua Tembien district, Tigray, Northern Ethiopia: a community-based case-control study. PLoS One 2018;13:e0200898.

Bearak J, Popinchalk A, Alkema L, and Sedgh, G.(2018). Global, regional, and sub-regional trends in unintended pregnancy and its outcomes from 1990 to 2014: estimates from a Bayesian hierarchical model. The Lancet Global Health. 2018 April 16(4), 9-380

Blerta, P. Peer influence and Adolescent sexual Behaviour Trajectories (2017). links to sexual initiation. European Journal of multidisciplinary studies. 2017;P (2) 3

Darroch JE, Woog V, Bankole A, Ashford L., S, Points K. (2016). Adding it up: Costs and benefits of meeting the contraceptive needs of adolescents. New York: Guttmacher https://www.guttmacher.org/report/adding-itmeeting-contraceptive-needs-ofadolescents.html

Demographic Health Survey Nigeria 2018 https://www.dhsprogram.com/pubs/pdf/FR359/FR359.pdf

Envuladu E.A, Agbo H.A, Ohize V.A, Zoakah A.I. (2014). Determinants and Outcome of Teenage Pregnancy in a Rural Community in Jos, Plateau State, Nigeria; Sub-Saharan African Journal of Medicine 2014; 1(1):47-52.

Ethiopia Demographic and Health Survey; (2016). https://dhsprogram.com/pubs/pdf/FR328/FR328.pdf

Folayan M.O, Adebajo S. Adeyemi, A. and Ogungbemi K.M. (2015). Differences in Sexual Practices, Sexual Behavior and HIV Risk Profile between Adolescents and Young Persons in Rural and Urban Nigeria 2015; 10(7): 0129106.

Ghana Statistical Service. (2015). Population and Housing Census: National Analytical 2010. https://statsghana.gov.gh/gssmain/fileUpload/pressrelease/2010_PHC_National_Analyti cal_Report.pdf.

Godwin J, Szabo G, Sass J, and Sauvarin J. (2014). Righting the mismatch between law, policy and sexual and reproductive health needs of young people in the Asia-Pacific region. Reproductive Health Matters. 2014; 22(44):47-137

Kuyinu YA, Femi-Adebayo TT, Odugbemi BA, et. (2017). Causative factors for sexual and reproductive health status of pregnant adolescent girls in urban communities of Lagos, Nigeria. International Journal Adolescents Medicine Health 2017

Mothiba TM, Maputle MS. (2012). Factors contributing to teenage pregnancy in the Capricorn district of the Limpopo Province. Curationis, 2012; 35,19.

Nwabueze S.A, Azuike E.C, Ezenyeaku C.A, Aniagboso C.C, Azuike, E.D. and Iloghalu I.C. (2014). Perception of Sexually Transmitted Infection-Preventive Measures among Senior Secondary School Students in Nnewi-North Local Government Area, Anambra State, Nigeria. Open Journal of Preventive Medicine. 2014; (4)708-716.

Nwosu, U.M. (2017). "Contemporary factors of teenage pregnancy in rural communities of Abia state, Nigeria," International Journal Of Community Medicine And Public Health, 2017; 4, 588-592.

Ochiogu IN, Miettola J,\& Ilika AL.(2011). Impact of timing of sex education on teenage pregnancy in Nigeria: cross-sectional survey of secondary school students. Journal of Community Health, 2011; 36, 375-80

Onyeka I.N. Miettola J. Ilika A.L. and Vaskilampi. T. (2011). Unintended Pregnancy and Termination of Studies among Students in Anambra State, Nigeria. African Journal of Reproductive Health. 2011; (15) 109. 
African Journal of Health, Nursing and Midwifery

ISSN: 2689-9418

Volume 4, Issue 3, 2021 (pp. 45-53)

www.abjournals.org

Sule H.A, Akor J.A, Toluhi O.J, Suleiman R.O, Akpihi L, and Ali O.U. (2015) Impact of Sex Education in Kogi State, Nigeria. Journal of Education and Practice. 2015; 6(3) 17352222.

WHO. Global health estimates (2015): deaths by cause, age, sex, by country and by region, 2000-2015. Geneva:

https://www.who.int/healthinfo/global_burden_disease/estimates_regional_2000_2015/ en/

World Health Organization. Adolescent development. (2018). www.unfpa.org>resources>givingspecialattentiongirls2020.

World Health Organization. Adolescent Pregnancy. Geneva: WHO, 2014 https://www.who.int/news-room/fact-sheets/detail/adolescent-pregnancy, 